\title{
Acute hospitalization in a cohort of patients with systemic sclerosis: a 10-year retrospective cohort study
}

\author{
Joana Caetano $^{1,2} \mathbb{E} \cdot$ Frederico Batista $^{1,2} \mathbb{D} \cdot$ Marta C. Amaral $^{1,2} \mathbb{D} \cdot$ Susana Oliveira $^{1}$ D $\cdot$ José $^{D} \cdot$ Alves $^{1,2} \mathbb{D}$
}

Received: 21 June 2021 / Accepted: 28 August 2021 / Published online: 3 September 2021

(c) The Author(s), under exclusive licence to Springer-Verlag GmbH Germany, part of Springer Nature 2021

\begin{abstract}
This study aimed at analysing the causes and predictors of acute hospitalization and mortality in a cohort of SSc. Retrospective analysis of all acute hospital admissions of SSc patients fulfilling the 2013 EULAR/ACR Classification Criteria, from a single-centre cohort of 95 patients, between 2010 and 2020. The total number of SSc patients registered in our hospital, in this period, was 123. Clinical data were collected from medical files of our institution and from the National Healthcare Registry platform. 53 patients needed acute hospitalization, in a total of 164 admissions. The most frequent causes for admission were: infectious diseases [27\%; 70\% due to pneumoniae, of which 74\% had SSc-associated interstitial lung disease (ILD)], cardiac disease (16.5\%), peripheral vascular disease [12.8\%; all due to digital ulcers], pulmonary hypertension (PH) (9.8\%) and ILD $(9.1 \%)$. There was an increase in admissions due to cardiac disease over the 10 years of follow-up, and a decrease of ILD over the last 5 years. Fourteen patients died (in-hospital mortality of 9\%) mainly due to pneumoniae (36\%), heart failure (21\%), neoplastic diseases (21\%), PH (14\%) and ILD (7\%). From all the admissions due to infection 70.5\% were under immunosuppression at the time of the hospitalization. The frequency of acute admissions superior to 1 was associated with infection (OR 2.29, 95\%CI 1.11-4.71). There were several factors associated with both acute admissions and mortality, including: gender, race, digital ulcers, cardiac dysfunction, ILD and PH. Infection was the principal cause of acute hospitalization and mortality, mainly due to pneumoniae. Although a high percentage of those had ILD, it has been decreasing in the last years in our cohort, as a direct cause of hospital admission and mortality, possibly reflecting the advances in its management.
\end{abstract}

Keywords Systemic scleroderma $\cdot$ Outcome assessment $\cdot$ Hospitals $\cdot$ Inpatients $\cdot$ Infections

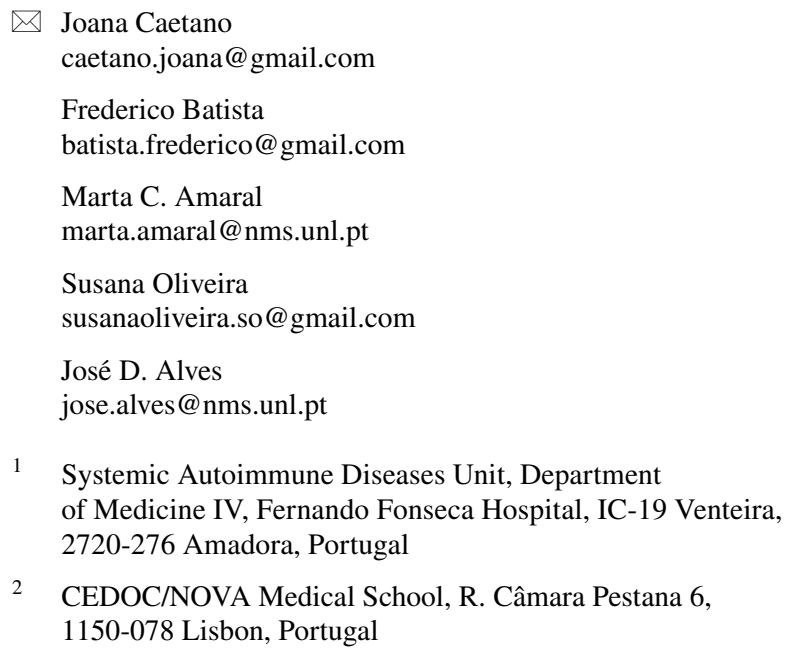

1 Systemic Autoimmune Diseases Unit, Department of Medicine IV, Fernando Fonseca Hospital, IC-19 Venteira, 2720-276 Amadora, Portugal

2 CEDOC/NOVA Medical School, R. Câmara Pestana 6, 1150-078 Lisbon, Portugal

\section{Introduction}

Systemic sclerosis ( $\mathrm{SSc}$ ) is associated with significantly high morbidity and mortality rates.

Most studies in SSc have analyzed disease complications and survival in outpatient cohorts [1-3]. There are very few reports [4-6] evaluating acute hospitalization patterns of SSc cohorts, other than in intensive care units [7, 8], or related to specific complications of SSc, namely pulmonary hypertension and interstitial lung disease $[9,10]$. Moreover, most of these studies are from more than a decade ago [11-14], and as such, they do not reflect the impact on survival of SSc patients of recent advances in the management and treatment of different aspects of this disease [15].

Our aim was to analyze the causes and predictors of acute hospitalizations and inpatient mortality, in a cohort of SSc patients. 


\section{Methods}

We performed a retrospective review of all the 95 patients with SSc fulfilling the 2013 EULAR/ACR Classification Criteria followed in our Unit between January 2011 and December 2020. The total number of SSc patients registered in our hospital, in this time-period, was 123. Only acute admissions, i.e. hospitalizations due to unexpected conditions needing of urgent treatment, were considered. Our Unit has a specific clinic for SSc patients, integrated in an Internal Medicine department with a dedicated ward and direct access to the emergency department and intensive care unit. All acute hospitalizations were considered, even if they occurred outside our institution. Patient's records due to elective admissions (programmed treatment administration, or needing of a specific complementary diagnostic test, for example) were excluded from this analysis.

Clinical data were collected from the patients' medical files of our Unit and from the National Healthcare Registry Platform.

The patients' characteristics analyzed were as following: age at SSc diagnosis, gender, race, duration of SSc (from the first non-Raynaud's phenomenon symptom)), skin disease subtype, autoantibodies, prevalence of Raynaud's phenomenon and organ involvement, including digital ulcers (DU), calcinosis, musculoskeletal symptoms, gastrointestinal involvement, interstitial lung disease (ILD), pulmonary hypertension (PH), cardiac involvement [left ventricular (LV) systolic and diastolic dysfunction and right ventricular (RV) dysfunction based on the last transthoracic echocardiogram available] and SSc-associated renal crisis. Immunosuppressive therapy, comorbidities, death, and cause of death were also reviewed.

For patients who add at least one acute hospital admission further variables were collected was as following: age at the first admission, duration of SSc at first admission, cause of hospitalization, number of acute admissions for each patient, length of stay of each admission and type of department where the patients were admitted.

This study was performed in accordance with the ethical standards of our institutional research ethics committee and with the 1964 Helsinki declaration and its later amendments.

\section{Statistical analysis}

Categorical data were presented as counts and percentages. Between-group comparisons of baseline covariates were performed with the Chi square test or Fisher exact test, as appropriate. Normality of the continuous data was tested with Kolmogorov-Smirnov test. The skewed distributions were described with medians and interquartile ranges (IQR) and were compared with the use of the Wilcoxon rank-sum test and Kruskal-Wallis test. Normal distributions were described with means and standard deviations and were compared with the use of student's $t$ test. The two-sided alpha level was set at 0.05 .

Since patients could have more than one admission, we assessed the effect of time until discharge (length of stay) longitudinally with multivariable generalized estimating equations to logistic regression analysis with repeated measures. This allowed for analysis with multiple admissions per patient correcting for the characteristics of a single individual over time. We used multivariable logistic and regression models for the primary analysis to determine possible associations with the development of hospital admission, and infection and mortality during the hospital stay. Variables were entered into the models when the alpha level of the risk factor was less than 0.10 in univariable analysis and if they were clinically relevant. Odds ratio (OR) and $95 \%$ confidence interval (CI) were calculated. We evaluated mortality in our cohort with a survival analysis using Cox proportional hazard regression models for univariable and multivariable analysis and to determine the hazard ratios (HR) and 95\%CI. The proportional hazard assumption was evaluated by plotting Schoenfeld residuals as a function of time. Furthermore, we tested the assumption of proportionality by using generalised linear regression of the scaled Schoenfeld residuals on functions of time to test for a non-zero slope.

Prediction models for multivariable analysis were developed with a stepwise selection. Variables entered the models when the alpha level of the risk factor was less than 0.10 in univariable analysis and if they were clinically relevant. Odds ratio (OR) and 95\% confidence interval (CI) were calculated.

Analyses were conducted using STATA software, version $14.0\left(\right.$ StataCorp $\left.^{\circledR}\right)$.

\section{Results}

Of the 95 patients included in this cohort analysis, $53(56 \%)$ patients needed acute hospitalization in a total number of 164 admissions. Most of the admissions were in a medical department $(73.2 \%)$, and during the stay, $6.8 \%$ needed admission in the ICU (Table 1).

The most frequent causes were infectious diseases in $27 \%$ ( $70 \%$ of them were pneumoniae), cardiac diseases in $16.5 \%$ (heart failure in 55.6\%), peripheral vascular disease in $12.8 \%$ (all due to DU and Raynaud's phenomenon, needing intravenous iloprost) and pulmonary hypertension in 9.8\%. Lung disease was also a recurrent cause of admission $(9.1 \%)$, in 
Table 1 Number of admissions, length of stay, mortality and causes of hospitalization

\begin{tabular}{ll}
\hline Variable* & $\begin{array}{l}\text { Hospital- } \\
\text { ized SSc } \\
N=53\end{array}$ \\
\hline Total number of admissions & 164 \\
Number of admissions/Patient, n (SD) & $3.1(2.8)$ \\
Length of stay, days, mean (SD) & $10.8(12.7)$ \\
In-Hospital mortality & $14(9)$ \\
Hospital department of admission & \\
Medical department & $120(73.2)$ \\
Surgical department & $7(4.3)$ \\
Emergency department & $37(22.6)$ \\
Need of ICU admission & $11(6.8)$ \\
Principal cause for hospitalization & \\
Infectious diseases & $44(27.0)$ \\
Cardiac diseases & $27(16.5)$ \\
Peripheral vascular diseases & $21(12.8)$ \\
Pulmonary Hypertension & $16(9.8)$ \\
Lung diseases & $15(9.1)$ \\
Hematologic diseases & $8(4.9)$ \\
Gastrointestinal diseases & $8(4.9)$ \\
Musculoskeletal diseases & $6(3.7)$ \\
Kidney diseases & $5(3.0)$ \\
Surgical diseases & $4(2.4)$ \\
Neoplastic diseases & $3(1.8)$ \\
Obstetric diseases & $3(1.8)$ \\
Neurologic diseases & $2(1.2)$ \\
Psychiatric diseases & $2(1.2)$ \\
\hline & \\
\hline &
\end{tabular}

$I C U$ intensive care unit; $S D$ standard deviation; SSc systemic sclerosis ${ }^{*}$ variables expressed as number $(n)$ and percentage (\%), unless otherwise explained

patients with a progressive (previously established or newly diagnosed) ILD without undercurrent infection.

In the first 5 years of follow-up, the total number of hospitalizations increased, pairing with an increase in cardiac and infectious diseases as the main reasons for admission (Fig. 1A, B), whilst ILD as a direct cause of hospitalization decreased in the last five years (2016-2020).

Comparing with the non-hospitalized SSc patients (Table 2), hospitalized patients had more diffuse cutaneous disease $(p=0.03)$ were more frequently positive for anti-scl70 antibodies $(p=0.05)$, had more digital ulcers $(p=0.02)$, ILD $(p=0.01), \mathrm{PH}(p=0.03)$ and cardiac dysfunction (both of left and right ventricles, $p=0.02$ and $p=0.03$, respectively).

In multivariable analysis (Table 3), only digital ulcers (OR 6.29, 95\% CI 1.6-24.8, $p<0.01$ ) and diastolic LV dysfunction (OR 7.34, 95\%CI 1.6-33.6, $p=0.01)$ were associated with the need for acute hospital admission. Furthermore, in this analysis, female (OR 0.1, 95\%CI 0.01-0.71, $p=0.02$ ) and caucasian patients (OR 0.06, 95\% CI $0.004-0.95, p=0.05$ ) had lower odds of hospitalization, as well as patients treated with methotrexate (OR 0.09 95\%CI $0.02-0.5, p<0.01)$.

\section{In-hospital mortality}

All the deaths in our cohort were from the group of patients that had to be hospitalized at any point of the follow up ( $n=14$, Table 2$)$ and all of them occurred during the hospital stay (in-hospital mortality of 9\%). The causes of death were: pneumoniae (36\%), heart failure (21\%), neoplastic diseases $(21 \%)$, pulmonary hypertension $(14 \%)$ and progression of $\operatorname{ILD}(7 \%)$. Five of these deaths were in the ICU.

In univariable analysis (data not showed), we identified some potential characteristics with statistical significance forpredictors of mortality: older age $(p=0.03)$, diffuse cutaneous subtype $(p=0.02)$, positive anti-scl70 antibodies $(p=0.01)$, presence of calcinosis $(p=0.007)$, right ventricle dysfunction $(p=0.003)$, ILD $(p=0.02)$ and $\mathrm{PH}(p=0.003)$. A higher number of hospital admissions $(p=0.01)$ and at least one admission due to infection $(p=0.03)$ were also associated with a higher mortality. Immunosuppression, regardless of the type of treatment, did not associate with mortality $(p=0.14)$. female gender $(\mathrm{HR}=0.15$; 95\%CI: 0.04-0.49); age at diagnosis of SSc (HR 1.07; 95\%CI: $1.02-1.11$ ), duration of disease (HR $0.88,95 \% \mathrm{CI}$ : 0.81-0.97); positive anti-scl70 antibodies (ATA) $(\mathrm{HR}=4.29$; 95\%CI: $1.43-12.91)$, ILD (HR $=5.02$; 95\% CI: 1.37-18.46), $\mathrm{PH}(\mathrm{HR}=3.77$; 95\%CI: $1.20-11.84)$ and right ventricle dysfunction $(\mathrm{HR}=5.36$; 95\% CI: 1.75-16.40). Immunosuppression, regardless of the type of treatment, did not associate with mortality $(p=0.20)$.

In the multivariable analysis, using a stepwise selection model, female gender ( $\mathrm{HR}=0.21,95 \% \mathrm{CI}$ : 0.05-0.91), duration of disease (HR $=0.80 ; 95 \% \mathrm{CI}: 0.70-0.92)$ and right ventricle dysfunction ( $\mathrm{HR}=5.04 ; 95 \% \mathrm{CI}: 1.36-18.62)$ had statistical significance for death from any cause (Table 4.).

In multivariable analysis however, none of the variables studied were associated with mortality (Table 3 ).

\section{Infection as one of the most frequent causes of acute admission and mortality}

The number of acute admissions due to infection was 44 (27\% of the total number of hospitalizations), and its frequency increased throughout the years of follow-up. Of these infections, the most frequent was pneumoniae in 31 admissions, of which $74 \%$ had SSc-associated ILD. RGE was not more frequent in patients admitted for pneumoniae comparing with patients admitted for other causes $(p=0.54)$. The most common pathogens identified in patients with pneumoniae, were Streptococcus pneumoniae $(n=3)$, Haemophilus 
Fig. 1 (A) Yearly number of acute admissions and proportion of hospitalized patients; (B) Yearly evolution of the 4th most frequent causes of acute hospital admissions
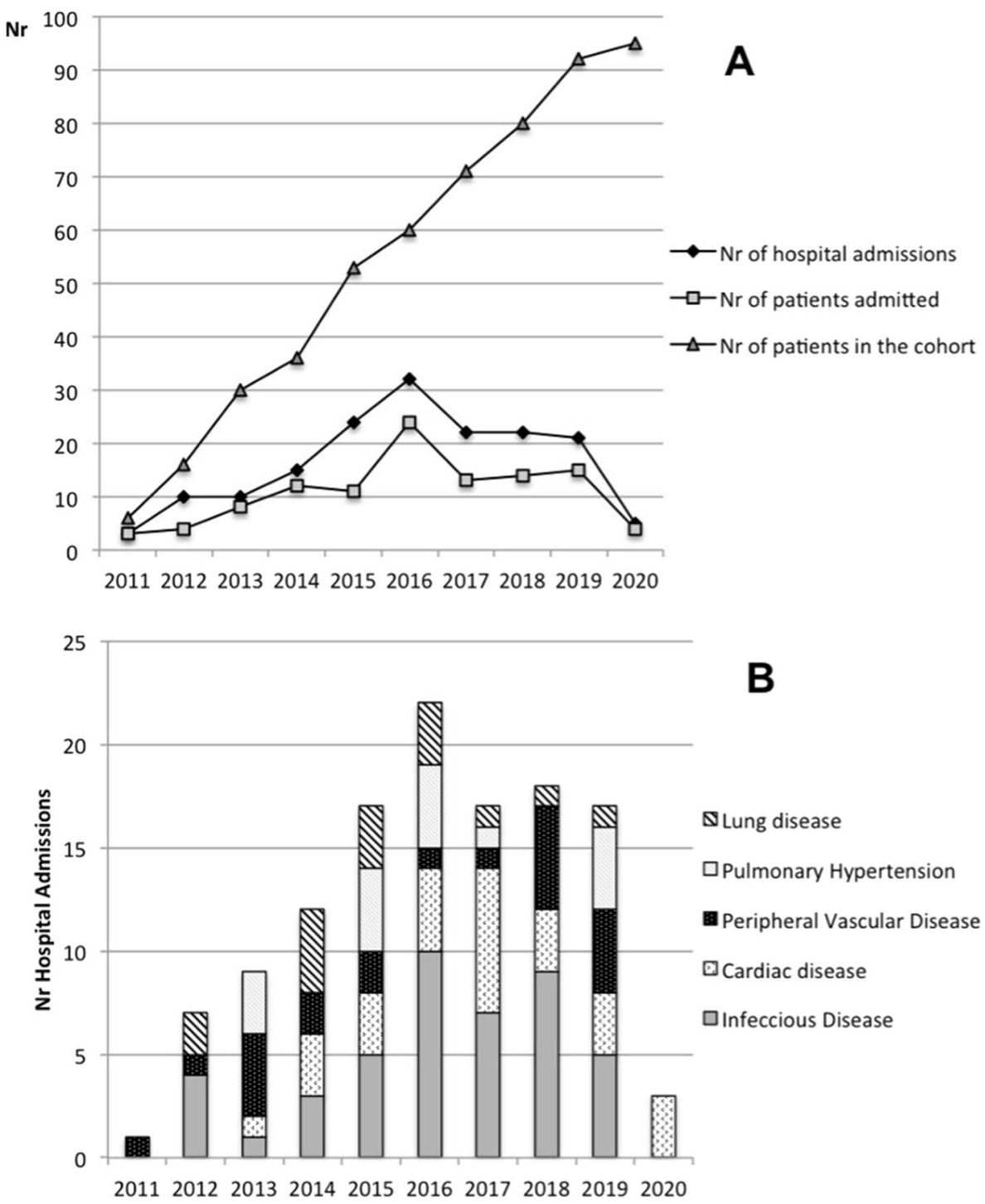

influenza $(n=3)$, Pseudomonas aeruginosa $(n=2)$ and methicillin-sensitive Staphylococcus aureus $(n=1)$.

Less common infections were pyelonephritis ( 7 admissions) and acute gastroenteritis (4 admissions). In these infections, the pathogens identified were, pyelonephritis: Escherichia coli $(n=4)$, Enterococcus faecalis $(n=2)$, Pseudomonas aeruginosa $(n=1)$; acute gastroenteritis: Campylobacter jejuni $(n=2)$.

From all these 44 admissions due to infectious diseases, in $31(70.5 \%)$ the patients were under immunosuppression at the time of the hospitalization. Five cases needed ICU stay, all due to pneumoniae.

Vaccination status was reviewed in all the patients admitted due to infectious diseases. All had updated immunization accordingly to the national immunization schedule. Considering the admissions due to pneumoniae, 26 had the influenza vaccine and 13 had the pneumococcal polysaccharide vaccine (PPSV23).
In univariable analysis, baseline patients' characteristics that were associated with infection were: diffuse cutaneous subtype $(p=0.010)$, positive anti-scl70 antibodies $(p=0.014)$, calcinosis $(p=0.02)$, right ventricle dysfunction $(p=0.036)$, ILD $(p=0.008)$, and MMF treatment $(p=0.009)$. However, in multivariable analysis (Table 3 ) none of these characteristics remained statistically significant, except the number of acute hospital admissions $>1$ (OR 2.29, 95\%CI 1.11-4.71, $p=0.02$ ).

\section{Discussion}

In this study we analyzed our cohort of SSc patients regarding acute hospital admission patterns. The clinical characteristics more frequently associated with hospitalization were a positive anti-scl70 antibody, diffuse cutaneous subtype, presence of DU, ILD, PH and cardiac involvement. 
Table 2 Baseline characteristics of the cohort

\begin{tabular}{|c|c|c|c|c|c|}
\hline Variable* & $\begin{array}{l}\text { Hospitalized SSc } \\
N=53\end{array}$ & $\begin{array}{l}\text { Non-Hospitalized } \\
\text { SSc } N=42\end{array}$ & OR & $\mathrm{CI}$ & $p$ \\
\hline Female & $43(81.1)$ & $39(92.9)$ & 0.33 & $0.08-1.29$ & 0.1 \\
\hline Caucasian & $46(86.8)$ & $41(97.6)$ & 0.16 & $0.02-1.31$ & 0.06 \\
\hline Age at SSc diagnosis, mean (SD) & $52.9(16.5)$ & $50.7(15.6)$ & 1.01 & $0.98-1.03$ & 0.51 \\
\hline Duration of SSc, mean (SD) & $9.8(6.8)$ & $8.3(6.8)$ & 1.04 & $0.97-1.10$ & 0.29 \\
\hline Age at 1 st admission, years, mean (SD) & $58.6(15.8)$ & - & - & - & - \\
\hline Duration of SSc at $1^{\text {st }}$ admission, years, mean (SD) & $5.7(6.8)$ & - & - & - & - \\
\hline Skin disease subtype & & & & & 0.03 \\
\hline Diffuse & $24(45.3)$ & $10(23.8)$ & 2.4 & $1.14-5.02$ & \\
\hline Limited & $29(54.7)$ & $32(76.2)$ & 0.91 & $0.55-1.50$ & \\
\hline ANA & $53(100)$ & $42(100)$ & - & - & - \\
\hline ACA & $17(32.7)$ & $20(47.6)$ & 0.53 & $0.21-1.34$ & 0.14 \\
\hline ATA & $13(25.0)$ & $4(9.5)$ & 3.17 & $0.87-14.37$ & 0.05 \\
\hline ARA & $7(13.5)$ & $7(16.7)$ & 0.78 & $0.21-2.88$ & 0.66 \\
\hline Raynaud's Phenomenon & $53(100)$ & $39(92.9)$ & 1.36 & $0.90-1.36$ & 0.05 \\
\hline Digital Ulcers & $22(41.5)$ & $8(19.0)$ & 3.02 & $1.08-8.93$ & 0.02 \\
\hline Calcinosis & $10(18.9)$ & $4(9.5)$ & 2.21 & $0.57-10.38$ & 0.2 \\
\hline Arthritis & $38(71.4)$ & $30(71.4)$ & 1.01 & $0.37-2.72$ & 0.97 \\
\hline Myositis & $11(20.8)$ & $4(9.5)$ & 2.49 & $0.66-11.52$ & 0.14 \\
\hline Esophageal Reflux & $41(77.4)$ & $27(64.3)$ & 1.9 & $0.70-5.17$ & 0.16 \\
\hline GAVE & $2(3.8)$ & $2(4.8)$ & 0.78 & $0.05-11.29$ & 0.81 \\
\hline Bowel Involvement & $12(22.6)$ & $4(9.5)$ & 2.78 & $0.75-12.73$ & 0.09 \\
\hline ILD & $28(52.8)$ & $8(19.0)$ & 4.76 & $1.72-13.99$ & 0.01 \\
\hline PH & $9(17.0)$ & $1(2.3)$ & 7.95 & $1.00-357.53$ & 0.03 \\
\hline Systolic dysfunction of LV & $7(13.5)$ & $0(0)$ & 1.15 & $0.75-1.77$ & 0.02 \\
\hline Diastolic dysfunction of LV & $21(40.4)$ & $6(15.4)$ & 3.73 & $1.23-12.64$ & 0.01 \\
\hline RV dysfunction & $9(17.0)$ & $1(2.3)$ & 7.95 & $1.00-357-53$ & 0.03 \\
\hline SRC & $1(2.0)$ & $1(2.3)$ & 0.79 & $0.01-63.38$ & 0.87 \\
\hline \multicolumn{6}{|l|}{ Comorbidities: } \\
\hline Arterial Hypertension & $22(41.5)$ & $14(33.3)$ & 1.42 & $0.56-3.61$ & 0.41 \\
\hline Diabetes & $9(17.0)$ & $3(7.1)$ & 2.66 & $0.60-16.19$ & 0.22 \\
\hline Lung disease $^{1}$ & $5(9.4)$ & $6(14.3)$ & 0.63 & $0.14-2.69$ & 0.53 \\
\hline Depression & $10(18.9)$ & $7(16.7)$ & 1.16 & $0.36-3.99$ & 0.9 \\
\hline Neoplasia & $3(5.7)$ & $4(9.5)$ & 0.57 & $0.08-3.61$ & 0.7 \\
\hline Immunosuppression & $29(54.7)$ & $27(64.3)$ & 0.67 & $0.27-1.67$ & 0.35 \\
\hline MTX & $8(15.1)$ & $18(42.9)$ & 0.24 & $0.08-0.68$ & $<0.01$ \\
\hline MMF & $18(34.0)$ & $8(19.0)$ & 2.19 & $0.77-6.58$ & 0.1 \\
\hline CYC & $6(11.3)$ & $2(4.8)$ & 2.55 & $0.42-26.99$ & 0.25 \\
\hline TCZ & $7(13.2)$ & $2(4.8)$ & 3.04 & $0.53-31.33$ & 0.16 \\
\hline RTX & $3(5.7)$ & $0(0)$ & 1.19 & $0.79-1.79$ & 0.25 \\
\hline Death & $14(26.4)$ & $0(0)$ & 31.2 & $1.80-540.65$ & $<0.01$ \\
\hline
\end{tabular}

$A C A$ anticentromere antibodies; $A N A$ antinuclear antibodies; $A R A$ anti-RNA polymerase III antibodies; $A T A$ anti-scl70 antibodies; $C I$ confidence interval; $C Y C$ cyclophosphamide; GAVE gastric antral vascular ectasia; ILD interstitial lung disease; $L V$ left ventricle; $M T X$ methotrexate; $M M F$ mycophenolate mofetil; $O R$ odds ratio; $P H$ pulmonary hypertension; $R V$ right ventricle; $R T X$ rituximab; $S D$ standard deviation; $S R C$ systemic sclerosis renal crisis; $S S c$ systemic sclerosis; $T C Z$ tocilizumab

*variables expressed as number $(n)$ and percentage $(\%)$, unless otherwise explained

${ }^{1}$ Lung disease not related to SSc, including asthma, sleep apnoea, chronic obstructive pulmonary disease and chest wall deformities with restrictive syndrome 
Table 3 Predictors of acute hospitalization, mortality and infection (multivariable logistic regression analysis)

\begin{tabular}{|c|c|c|c|c|c|c|}
\hline \multirow[t]{2}{*}{ Variable } & \multicolumn{3}{|c|}{ Acute hospitalization } & \multicolumn{3}{|c|}{ Infection } \\
\hline & OR & $\mathrm{CI}$ & $p$ & OR & $\mathrm{CI}$ & $p$ \\
\hline Female & 0.10 & $0.01-0.71$ & 0.02 & 0.07 & $0.04-1.03$ & 0.05 \\
\hline Caucasian & 0.06 & $0.004-0.95$ & 0.05 & 67.35 & $0.48-9490.3$ & 0.06 \\
\hline Age at Admission & - & - & - & 1.10 & $0.90-1.34$ & 0.35 \\
\hline Age at SSc diagnosis & - & - & - & 0.99 & $0.81-1.20$ & 0.91 \\
\hline Diffuse skin subtype & 2.16 & $0.78-8.17$ & 0.25 & 0.38 & $0.03-4.53$ & 0.44 \\
\hline ATA & 0.82 & $0.1-4.5$ & 0.82 & - & - & - \\
\hline ACA & - & - & - & 0.04 & $0.01-1.08$ & 0.06 \\
\hline Digital Ulcers & 6.29 & $1.6-24.8$ & $<0.01$ & - & - & - \\
\hline Calcinosis & - & - & - & 1.56 & $0.04-54.94$ & 0.81 \\
\hline Bowel Involvement & 1.80 & $0.3-10.3$ & 0.51 & - & - & - \\
\hline ILD & 1.84 & $0.5-7.2$ & 0.38 & 1.00 & $0.07-24.78$ & 1.00 \\
\hline $\mathrm{PH}$ & 1.80 & $0.3-198.8$ & 0.23 & - & - & - \\
\hline Systolic dysfunction of LV & - & - & - & - & - & - \\
\hline Diastolic dysfunction of LV & 7.34 & $1.6-33.6$ & 0.01 & - & - & - \\
\hline RV dysfunction & 0.49 & $0.2-13.5$ & 0.68 & 6,94 & $0.49-98.19$ & 0.15 \\
\hline AHT & - & - & - & 6.29 & $0.47-84.00$ & 0.16 \\
\hline Treatment with MMF & - & - & - & 1.75 & $0.05-60,97$ & 0.76 \\
\hline Treatment with MTX & 0.09 & $0.02-0.5$ & $<0.01$ & - & - & - \\
\hline $\mathrm{Nr}$ admissions $(>1)$ & - & - & - & 2.29 & $1.11-4.71$ & 0.02 \\
\hline $\operatorname{Nr}$ Infection $(\geq 1)$ & - & - & - & - & - & - \\
\hline
\end{tabular}

$A C A$ anticentromere antibodies; $A H T$ arterial hypertension; $A T A$ anti-scl70 antibodies; $C I$ confidence interval; $I L D$ interstitial lung disease; $L V$ left ventricle; $M T X$ methotrexate; $M M F$ mycophenolate mofetil; $N r$ number; $O R$ odds ratio; $P H$ pulmonary hypertension; $R V$ right ventricle; $S S c$ systemic sclerosis
Table 4 Survival analysis (Cox proportional hazard model, multivariable analysis)

\begin{tabular}{llll}
\hline Variable & HR & CI & $p$ \\
\hline Female & 0.21 & $0.05-0.91$ & 0.037 \\
Duration of SSc & 0.80 & $0.70-0.92$ & 0.002 \\
Age at admission & 1.07 & $1.01-1.12$ & 0.017 \\
RV dysfunction & 5.04 & $1.36-18.62$ & 0.015 \\
\hline
\end{tabular}

$C I$ confidence interval, $H R$ hazard ratio, $R V$ right ventricule; $S S c$ systemic sclerosis

However, causes of acute admission changed over time, and are different from those reported in studies prior to 2010. In our cohort there was a higher percentage of hospitalizations due to infection (27\%) and cardiac disease (16.5\%), and not ILD as reported in other studies [13, 14, 16]. Tables 4, 5 summarizes published studies on hospitalization of patients with systemic sclerosis.

Piga M. et al. [14] performed an annual trend analysis showing a statistically significant increase in the percentage of ILD $(p<0.0001)$, PAH $(p<0.0024)$, digital ulcers, and gangrene $(p=0.0037)$, between the years of 2001-2012. In a study by Shenavandeh S. et al. [16] including 181 patients and 446 admissions, comprising a total of 13 years of follow-up (1999-2012), the most common causes of hospitalization were DU in 39.7\%, and interstitial lung disease and $\mathrm{PH}$ in $21.1 \%$. Additionally, ILD and PH were the most frequent causes of mortality in $33.3 \%$ of the cohort. In fact, other studies have also reported ILD as one of the main predictors of mortality in hospitalized patients with systemic sclerosis. Nietert PJ et al. in 2001, reported ILD as a predictor of in-hospital death, with an odds ratio of $2.67 ; 95 \% \mathrm{CI}$ 1.73-4.12. In the study of Chung $L$ et al. [13], published in 2007, ILD increased the odds of in-hospital mortality by 2.63 ; $95 \%$ CI $1.98-3.49$.

Data from our cohort shows that ILD, although being still a frequent cause of acute hospitalization, has been decreasing over the last 5 years. This can be the result of a more effective treatment approach following the results of clinical trials such as the Scleroderma Lung Study II [17] and SENSCIS [18], as well as due to an earlier recognition of lung involvement in these patients [15]. As presented in Fig. 1A the total number of patients in our cohort increased throughout the years of this analysis. We acknowledge that this increased number might have led to an increased awareness, and to an early identification of SSc cases, with lower prevalence of ILD. Nevertheless, our cohort has a similar frequency of organ involvement, namely of interstitial lung disease, as the one reported in other studies. In EUSTAR 


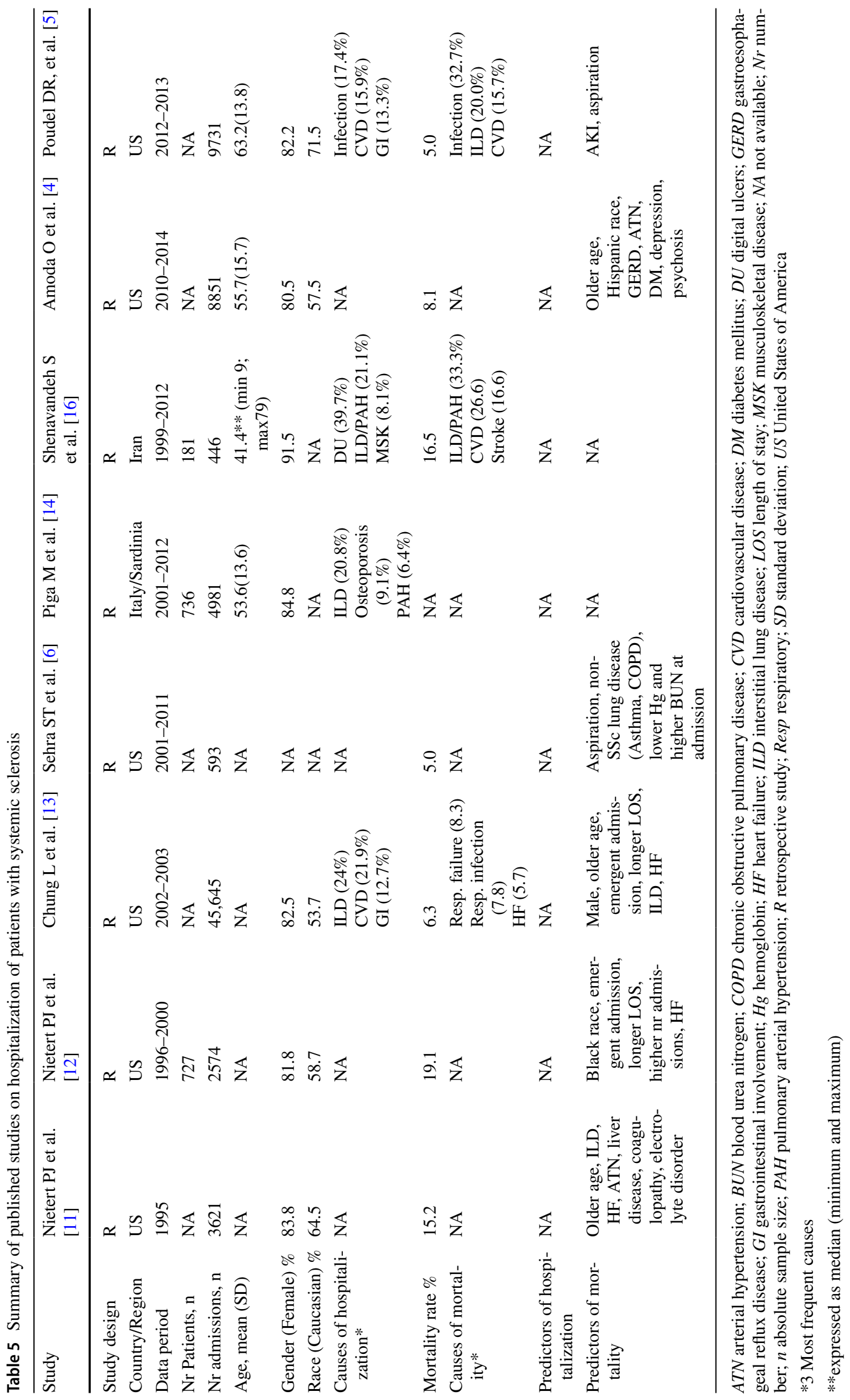


cohort [19] the prevalence of lung fibrosis on HRCT was $51.9 \%$, while in our hospitalized patients it was $52.8 \%$.

Infection was the leading cause for hospitalization and mortality in our patients, which is in line with a recent report of Poudel DR et al. reporting from a National Inpatient Sample database from the USA, regarding data from 2012 and 2013. Infections in this study were the most common diagnosis among SSc hospitalizations (17.4\%), and as cause of mortality $(32.7 \%)$. The rate of hospitalization due to infection in the other studies described in Table 5(4), with data collection prior to 2012, was low, ranging from $5.5 \%$ for respiratory infection and $2.13 \%$ for systemic infection in the study by Chung $\mathrm{L}$ et al. [13] and $4.4 \%$ for total infections in the study of Piga M et al. [14].

We can hypothesize that the crescent use of immunosuppression can lead to higher rates of infection. In our cohort, univariable analysis showed that MMF treatment was associated with infection, although this was not confirmed in multivariable analysis. It is possible that this data reflect more the severity of hospitalized SSc patients, with more organ involvement, especially ILD, since in our treatment protocol we use MMF in almost all patients with lung fibrosis. Poudel DR et al. also reported that aspiration mechanisms were strongly associated with in-hospital mortality $(\mathrm{OR}=3.5,95 \%$ CI: 2.5-4.9). Similarly, Sehra et al. reported that aspiration events were associated with higher inpatient mortality (OR 30, 95\% CI 3.58-250.80). In our work, due to the retrospective analysis, it was not possible to identify the true prevalence of aspiration. Nonetheless, esophageal reflux was not more frequent in patients who were hospitalized due to pneumoniae and was not related with in-hospital mortality. Another factor that may contribute to infection and mortality, is the higher number of hospitalizations, probably due to the increased exposure of patients to nosocomial infection agents. In our multivariable analysis a higher number of admissions increased the odds of infection by 2.29; 95\% CI 1.11-4.71, while in a study by Nietert PJ et al. [12] more than 1 prior hospitalization was predictor of mortality (odds ratio 2.28; 95\% CI 1.29-4.03).

Given the importance of infection for hospitalization in our cohort, a curious finding was that immunosuppression with methotrexate was associated with a lower odd of hospitalization (OR 0.09 ; 95\% CI 0.02-0.5). This fact similarly to the findings of MMF, might reflect more a bias related to our treatment protocol, as MTX is used only for patients with arthritis or cutaneous involvement, excluding those with internal organ involvement such as cardiac disease or ILD.

Our results also highlight the impact of cardiac dysfunction and pulmonary hypertension, which were some of the most frequent causes of hospitalization and of inpatient mortality. In univariable analysis cardiac dysfunction (systolic and diastolic dysfunction of the left ventricle) were associated with hospitalizations, although this only remained relevant in multivariable analysis for diastolic dysfunction (OR 7.34; 95\%CI 1.6-33.6). Although they do not differentiate between systolic or diastolic dysfunction, this is a universal finding in all the studies published on hospitalization of SSc patients [11-14, 16], in line with the current perception that primary cardiac involvement is often misdiagnosed, and that effective screening and treatment orientations are needed [20]. The prevalence of diastolic disfunction in SSc has been increasingly recognized, and associates with an increase mortality exceeding pulmonary hypertension in some cohorts [21, 22]. In a study from Hinchcliff $\mathrm{M}$ et al. LV diastolic dysfunction was present in $23 \%$ of the SSc patients (total of $153 \mathrm{SSc}$ patients), and it associated with mortality with hazard ratio (HR) of 3.2 (95\% CI 1.1-9.5). Furthermore, in the Oslo SSc cohort [22], diastolic dysfunction was also prevalent in $17 \%$ (46 of $275 \mathrm{SSc}$ patients), and it exceeded pulmonary hypertension in predicting mortality (HR 3.7; 95\%CI 1.69-8.14 for diastolic dysfunction vs. HR 2.0; 95\% CI 1.1-3.9 for PH).

Right ventricle dysfunction was also identified in our cohort as the stroger factor associated with mortality in survival analysis. Saito M, et al. demonstrated that right ventricule dysfunction was associated with a worse outcome (unplanned hospitalization and death) independently of incremental of LV dysfunction [23].

Another area of unmet needs in SSc management is the treatment and prevention of DU [24]. In a recent analysis from the Australian Scleroderma Cohort Study [25], SSc patients with a history of DU were responsible for an increased healthcare resources utilization, (including hospitalizations) and a higher associated cost than patients without DU. In our study, DU were the third most frequent cause of hospital admission (41.5\%), and its presence was significantly associated with hospitalization in multivariable analysis (OR 6.29; 95\% CI 16-24.8). DU were the most frequent cause of hospitalization reported by Shenavandeh $\mathrm{S}$ et al. [16] justifying 39.7\% of the admissions. Most of the other studies published reported a lower prevalence of DU, as a cause for hospitalization, varying between $1.43 \%$ [13] and $4.1 \%$ [14]. Some reasons for this difference might be the prevalence of background medication such as endothelin-1 antagonists or prostacyclin agonists, which was not registered in our study, and it was also not reported in the other studies.

Regarding the mechanisms of vasculopathy in SSc and the relevant role of environmental exposure, it is important to emphasize the reduced number of admissions during the year of 2020. One may hypothesize that due to the SarsCov-2 pandemic and the subsequent lockdown, patients were less exposed to those factors, especially to cold temperatures, and as such, there were no admissions due to DU or infections (probably due to mask use, and less person-toperson viral transmission). 
Another possible explanation would be the overwhelming use of the healthcare system in the context of the COVID pandemic resulting in less admissions for the remaining patients. We believe that this was not the case as all the patients were continuously followed during this period (with both telephone and in-patient appointments) and none of them effectively needed to be admitted.

Apart from SSc disease-complications and comorbidities, some demographic characteristics were also identified in our multivariable analysis as predictors of hospitalization, such as gender and race. In our cohort, female patients had a lower odd of hospitalization (odds ratio $0.10 ; 95 \% \mathrm{CI}$ 0.01-0.7), as well as caucasian patients (odds ratio 0.006; 95\%CI 0.004-0.95). Furthermore, in the survival analysis of our cohort, female patients had an HR of 0.21 ; $95 \% \mathrm{CI}$ 0.05-0.93., although we could not demonstrate the same association with mortality, probably due to the low number of patients. In fact, both gender and race have been identified as associated with hospitalization outcomes. Chung L et al. [13] reported an odds ratio of $0.69 ; 95 \% \mathrm{CI}$ $0.52-0.90$ for female gender as predictor of in-hospital mortality. Nietert PJ et al. [12] reported that black and other non-caucasian races had higher odd of in-hospital mortality: OR 1.7 ; 95\%CI 1.01-2.86 for black race and OR 2.06; 95\% CI1.04-4.09 for other races.

This study has several limitations. First, the number of patients and the number of admissions may have limited statistical analysis, namely the relevant associations with mortality in multivariable analysis, and of hospitalization with cardiac dysfunction. Furthermore, given the retrospective design, collection of data relies on registries made, although all the data were revised and subject of consistency check. Additionally, some acute admissions outside our institution might have been missed, despite the accuracy of our electronic national database.

In conclusion, in our cohort, infection was the principal cause of acute hospitalization and of inpatient mortality, mainly due to pneumoniae. Although a high percentage of those patients had ILD, this disease feature, in our cohort, has been decreasing over the last years as a direct cause of hospital admission and of mortality, probably reflecting the advances in its management. This study also reinforces the need of further research in DU and cardiac disease approach as those are still one of the main causes of hospitalization in SSc.

\section{Acknowledgements There are no acknowledgements to declare.}

Author contribution statement JC, FB, MA, SO and JDA gave substantial contributions to the conception or design of the work; or the acquisition, analysis, or interpretation of data for the work, drafted the work or revised it critically for important intellectual content; gave final approval of the version to be published; and gave agreement to be accountable for all aspects of the work in ensuring that questions related to the accuracy or integrity of any part of the work are appropriately investigated and resolved.

Funding No funding.

\section{Declarations}

Conflict of interest The authors declare no conflicts of interest.

Ethical standards All procedures performed involving human participants were in accordance with the ethical standards of our institutional research committee [Comissão de Ética para a Saúde (CES) do Hospital Prof. Dr. Fernando Fonseca] and with the 1964 Helsinki declaration and its later amendments.

\section{References}

1. Elhai M, Meune C, Avouac J, Kahan A, Allanore Y (2012) Trends in mortality in patients with systemic sclerosis over 40 years: a systematic review and meta-analysis of cohort studies. Rheumatology (Oxford) 51(6):1017-1026. https://doi.org/10.1093/rheum atology/ker269

2. Tyndall AJ, Bannert B, Vonk M, Airò P, Cozzi F, Carreira PE, Bancel DF, Allanore Y, Müller-Ladner U, Distler O, Iannone F, Pellerito R, Pileckyte M, Miniati I, Ananieva L, Gurman AB, Damjanov N, Mueller A, Valentini G, Riemekasten G, Tikly M, Hummers L, Henriques MJ, Caramaschi P, Scheja A, Rozman B, Ton E, Kumánovics G, Coleiro B, Feierl E, Szucs G, Von Mühlen CA, Riccieri V, Novak S, Chizzolini C, Kotulska A, Denton C, Coelho PC, Kötter I, Simsek I, de la Pena Lefebvre PG, Hachulla E, Seibold JR, Rednic S, Stork J, Morovic-Vergles J, Walker UA (2010) Causes and risk factors for death in systemic sclerosis: a study from the EULAR scleroderma trials and research (EUSTAR) database. Ann Rheum Dis 69(10):1809-1815. https://doi. org/10.1136/ard.2009.114264

3. Nihtyanova SI, Schreiber BE, Ong VH, Rosenberg D, Moinzadeh P, Coghlan JG, Wells AU, Denton CP (2014) Prediction of pulmonary complications and long-term survival in systemic sclerosis. Arthritis Rheumatol 66(6):1625-1635. https://doi.org/10.1002/ art.38390

4. Amoda O, Ravat V, Datta S, Saroha B, Patel RS (2018) Trends in demographics, hospitalization outcomes, comorbidities, and mortality risk among systemic sclerosis patients. Cureus 10(5):e2628. https://doi.org/10.7759/cureus.2628

5. Ram Poudel D, George M, Dhital R, Karmacharya P, Sandorfi N, Derk CT (2018) Mortality, length of stay and cost of hospitalization among patients with systemic sclerosis: results from the national inpatient sample. Rheumatology (Oxford) 57(9):16111622. https://doi.org/10.1093/rheumatology/key150

6. Sehra ST, Kelly A, Baker JF, Derk CT (2016) Predictors of inpatient mortality in patients with systemic sclerosis: a case control study. Clin Rheumatol 35(6):1631-1635. https://doi.org/10.1007/ s10067-016-3245-6

7. Shalev T, Haviv Y, Segal E, Ehrenfeld M, Pauzner R, Levy Y, Langevitz P, Shoenfeld Y (2016) Outcome of patients with scleroderma admitted to intensive care unit. A report of nine cases. Clin Exp Rheumatol 24(4):380

8. Pène F, Hissem T, Bérezné A, Allanore Y, Geri G, Charpentier J, Avouac J, Guillevin L, Cariou A, Chiche JD, Mira JP, Mouthon L (2015) Outcome of patients with systemic sclerosis in the intensive care unit. J Rheumatol 42(8):1406-1412. https://doi.org/10. 3899/jrheum.141617 
9. Hsu VM, Chung L, Hummers LK, Shah A, Simms R, Bolster M, Hant FN, Silver RM, Fischer A, Hinchcliff ME, Varga J, Goldberg AZ, Derk CT, Schiopu E, Khanna D, Shapiro LS, Domsic RT, Medsger T, Mayes MD, Furst D, Csuka ME, Molitor JA, Saketkoo LA, Salazar CR (2019) Risk factors for mortality and cardiopulmonary hospitalization in systemic sclerosis patients at risk for pulmonary hypertension, in the PHAROS registry. J Rheumatol 46(2):176-183. https://doi.org/10.3899/jrheum.180018

10. Noviani M, Saffari SE, Tan JL, Yip JWL, Teng GG, Law WG, Chan GYL, Santosa A, Lim AYN, Hong C, Ng SA, Tay ELW, Ruan W, Yap J, Low AHL (2020) Mortality and hospitalization outcomes of interstitial lung disease and pulmonary hypertension in the Singapore systemic sclerosis cohort. Semin Arthritis Rheum 50(3):473-479. https://doi.org/10.1016/j.semarthrit.2019.11.005

11. Nietert PJ, Silverstein MD, Silver RM (2001) Hospital admissions, length of stay, charges, and in-hospital death among patients with systemic sclerosis. J Rheumatol 28(9):2031-2037

12. Nietert PJ, Silver RM, Mitchell HC, Shaftman SR, Tilley BC (2005) Demographic and clinical factors associated with in-hospital death among patients with systemic sclerosis. J Rheumatology 32(10):1888-1892

13. Chung L, Krishnan E, Chakravarty EF (2007) Hospitalizations and mortality in systemic sclerosis: results from the Nationwide inpatient sample. Rheumatology (Oxford) 46(12):1808-1813. https://doi.org/10.1093/rheumatology/kem273

14. Piga M, Casula L, Sanna S, Perra D, Floris A, Antonelli A, Cauli A, Mathieu A (2016) Population-based analysis of hospitalizations for patients with systemic sclerosis in a West-European region over the period 2001-2012. Rheumatol Int 36(1):73-81. https://doi.org/10.1007/s00296-015-3330-1

15. Hoffmann-Vold AM, Maher TM, Philpot EE, Ashrafzadeh A, Barake F, Barsotti S, Bruni C, Carducci P, Carreira PE, Castellví I, Del Galdo F, Distler JW, Foeldvari I, Fraticelli P, George PM, Griffiths B, Guillén-Del-Castillo A, Hamid AM, Horváth R, Hughes M, Kreuter M, Moazedi-Fuerst F, Olas J, Paul S, Rotondo C, Rubio-Rivas M, Seferian A, Tomčík M, Uzunhan Y, Walker UA, Więsik-Szewczyk E, Distler O (2020) The identification and management of interstitial lung disease in systemic sclerosis: evidence-based European consensus statements. Lancet Rheumatol 2(2):e71-e83. https://doi.org/10.1016/S2665-9913(19)30144-4

16. Shenavandeh S, Naseri R (2017) Assessment of hospitalization and mortality of scleroderma in-patients: a thirteen-year study. Reumatologia 55(4):163. https://doi.org/10.5114/reum.2017. 69776

17. Tashkin DP, Roth MD, Clements PJ, Furst DE, Khanna D, Kleerup EC, Goldin J, Arriola E, Volkmann ER, Kafaja S, Silver R, Steen V, Strange C, Wise R, Wigley F, Mayes M, Riley DJ, Hussain S, Assassi S, Hsu VM, Patel B, Phillips K, Martinez F, Golden J, Connolly MK, Varga J, Dematte J, Hinchcliff ME, Fischer A, Swigris J, Meehan R, Theodore A, Simms R, Volkov S, Schraufnagel DE, Scholand MB, Frech T, Molitor JA, Highland K, Read CA, Fritzler MJ, Kim GHJ, Tseng CH, Elashoff RM; Sclerodema Lung Study II Investigators (2016) Mycophenolate mofetil versus oral cyclophosphamide in scleroderma-related interstitial lung disease
(SLS II): a randomised controlled, double-blind, parallel group trial. Lancet Respir Med 4(9):708-719. https://doi.org/10.1016/ S2213-2600(16)30152-7

18. Distler O, Highland KB, Gahlemann M, Azuma A, Fischer A, Mayes MD, Raghu G, Sauter W, Girard M, Alves M, Clerisme-Beaty E, Stowasser S, Tetzlaff K, Kuwana M, Maher TM; SENSCIS Trial Investigators (2020) Nintedanib for systemic sclerosis-associated interstitial lung disease. N Engl J Med 380(26):2518-2528. https://doi.org/10.1056/NEJMoa1903076

19. Meier FMP,Frommer KW, Dinser R, Walker UA, Czirjak L, Denton CP, Allanore Y, Distler O, Riemekasten G, Valentini G, Müller-Ladner U, EUSTAR Co-authors (2012) Update on the profile of the EUSTAR cohort: an analysis of the EULAR scleroderma trials and research group database. Ann Rheum Dis 71:13551360. https://doi.org/10.1136/annrheumdis-2011-200742

20. Cosimo B, Ross L (2021) Cardiac involvement in systemic sclerosis: getting to the heart of the matter. Best Pract Res Clin Rheumatol. https://doi.org/10.1016/j.berh.2021.101668

21. Hinchcliff M, Desai CS, Varga J, Shah SJ (2012) Prevalence, prognosis, and factors associated with left ventricular diastolic dysfunction in systemic sclerosis. Clin Exp Rheumatol 30(2 Suppl 71):S30-S37

22. Tennøe AH, Murbræch K, Andreassen JC, Fretheim H, Garen T, Gude E, Andreassen A, Aakhus S, Molberg Ø, HoffmannVold AM (2018) Left ventricular diastolic dysfunction predicts mortality in patients with systemic sclerosis. J Am Coll Cardiol 72(15):1804-1813. https://doi.org/10.1016/j.jacc.2018.07.068

23. Saito M, Wright L, Negish K, Dwyer N, Marwick TH (2018) Mechanics and prognostic value of left and right ventricular dysfunction in patients with systemic sclerosis. Eur Heart J Cardiov Imaging 19:660-667. https://doi.org/10.1093/ehjci/jex147

24. Smith V, Scirè CA, Talarico R, Airo P, Alexander T, Allanore Y, Bruni C, Codullo V, Dalm V, De Vries-Bouwstra J, Della Rossa A, Distler O, Galetti I, Launay D, Lepri G, Mathian A, Mouthon L, Ruaro B, Sulli A, Tincani A, Vandecasteele E, Vanhaecke A, Vanthuyne M, Van den Hoogen F, Van Vollenhoven R, Voskuyl AE, Zanatta E, Bombardieri S, Burmester G, Eurico FJ, Frank C, Hachulla E, Houssiau F, Mueller-Ladner U, Schneider M, van Laar JM, Vieira A, Cutolo M, Mosca M, Matucci-Cerinic M (2019) Systemic sclerosis: state of the art on clinical practice guidelines. RMD Open 4(1):e000782. https://doi.org/10.1136/ rmdopen-2018-000782

25. Morrisroe K, Stevens W, Sahhar J, Ngian GS, Ferdowsi N, Hill CL, Roddy J, Walker J, Proudman S, Nikpour M (2019) Digital ulcers in systemic sclerosis: their epidemiology, clinical characteristics, and associated clinical and economic burden. Arthritis Res Ther 21(1):1-12. https://doi.org/10.1186/s13075-019-2080-y

Publisher's Note Springer Nature remains neutral with regard to jurisdictional claims in published maps and institutional affiliations. 